\title{
Dialyzability, Protein Binding, and Renal Excretion of Plasma Conjugated Bilirubin *
}

\author{
Milford Fulor, $\dagger$ John Sandson, $\$$ and Paul Brazeau \\ (From the Departments of Medicine and Pharmacology, Albert Einstein College of Medicine \\ and the Bronx Municipal Hospital Center, New York, N. Y.)
}

Conjugated bilirubin is excreted in the urine, but unconjugated bilirubin is generally believed not to be excreted by the kidneys. The basis for this difference has not been resolved by past studies. Hoover and Blankenhorn reported that bilirubin was dialyzable only from the plasma of patients who had bilirubinuria, and that it was not dialyzable from the plasma of patients with acholuric jaundice (3). Most subsequent investigators, however, have maintained that neither conjugated nor unconjugated bilirubin was dialyzable or ultrafilterable from plasma (4-7). This led to the hypothesis that conjugated bilirubin was probably excreted in the urine by a process of renal tubular secretion (8).

Studies that were performed in jaundiced dogs in this laboratory gave results consistent with a process of glomerular filtration of conjugated bilirubin (9). We therefore re-examined the question of the dialyzability of plasma bilirubin. A small fraction of plasma conjugated bilirubin in jaundiced humans and dogs was found to be dialyzable, and hence available for urinary excretion by glomerular filtration. The studies indicated that this dialyzable fraction was bound to low molecular weight carrier(s), which migrated in the alpha and beta globulin zones on paper electrophoresis and which sedimented on ultracentrifugation.

* Submitted for publication August 20, 1964 ; accepted December 28, 1964.

Preliminary reports of portions of this work have been published $(1,2)$.

Supported by a grant from the U. S. Public Health Service (A-05503).

$\dagger$ Address requests for reprints to: Dr. Milford Fulop, Albert Einstein College of Medicine, Eastchester Road \& Morris Park Ave., New York 61, N. Y.

\#Investigator of the Health Research Council of the City of New York.

\section{Methods}

\section{Subjects}

The studies were performed in dogs and patients with obstructive jaundice. Jaundice was induced in the dogs by common bile duct ligation, and renal function studies were performed as described previously (9). In two dogs the right ureter was ligated at the time of the common bile duct operation, and the left ureter was operatively ligated about 10 days later. Both animals were sacrificed 2 days after the second procedure.

All of the patients had predominant conjugated hyperbilirubinemia ( 76 to $87 \%$ of total plasma bilirubin), as judged by the method of Weber and Schalm (10), or the 5-minute direct-reacting bilirubin. Jaundice was either waxing or stable in each patient.

The diagnoses included extrahepatic biliary obstruction, hepatitis, and cirrhosis. Renal function studies were performed after oral water loading, and urine was obtained by spontaneous voiding. The clearance of endogenous creatinine $\left(\mathrm{C}_{\mathrm{c}_{\mathbf{r}}}\right.$ ) was used to estimate glomerular filtration rate (GFR). Clearance values represent an average of two consecutive 1 -hour periods in most patients. Plasma bilirubin studies were conducted serially in some patients who were followed through a phase of renal failure during their terminal illness.

Clearance studies were performed in patients with plasma bilirubin levels between 9 and $32 \mathrm{mg}$ per $100 \mathrm{ml}$. The urinary excretion of nonbilirubin diazotizable substances was equivalent to the excretion of an average of $5.4 \mu \mathrm{g}$ of bilirubin per minute (range, 4.3 to 7.4 ) in six normal subjects. This represented less than $10 \%$ of the total urinary bilirubin excretion in almost all the jaundiced patients, and no correction was made for this blank. The nonbilirubin diazo blank in normal dog urine was of similar magnitude. Bilirubin clearance $\left(C_{B}\right)$ was calculated using total plasma bilirubin in the formula $U V / P$. None of the subjects received drugs known to interfere with the chemical methods or to affect the plasma protein binding of bilirubin. None of the subjects in whom clearance estimations were made, or whose urine was studied by electrophoresis or ultracentrifugation, had pathologic proteinuria as judged by testing with sulfosalicylic acid.

Plasma specimens with high levels of unconjugated bilirubin were prepared by dissolving bilirubin in $0.01 \mathrm{~N}$ $\mathrm{NaOH}$, adding an equal volume of $0.15 \mathrm{M}$ phosphate buffer ( $\mathrm{pH} 7.9)$, and then adding this bilirubin solution to normal human or dog plasma (final $\mathrm{pH} 8.3$ ). 


\section{Analytical}

A. Chemical. Bilirubin levels in plasma and urine were estimated by the diazotization method of Malloy and Evelyn (11) adapted for the Coleman junior spectrophotometer. Bilirubin in plasma dialyzates was estimated from $a$ ) the OD in the range 433 to $450 \mathrm{~m} \mu$ measured in a Zeiss PMQ II spectrophotometer in cuvettes of $5-\mathrm{cm}$ light path and $b$ ) the OD of the derivative violet azo pigment, measured in a Coleman senior or Zeiss spectrophotometer in cuvettes of $5-\mathrm{cm}$ light path. In a few of the more recent studies (see Figure 3 ), diazotization was accomplished using 1 vol of dialyzate and 1 vol of reagent without methanol. This method of performing the diazo reaction yielded higher optical density values than those obtained with the conventional proportions of $1: 6$ or $1: 9$ because of the smaller total volume containing the derivative azobilirubin. Bilirubin concentrations in jaundiced urine and in jaundiced uremic plasma dialyzates were almost identical whether estimated this way or by using the standard method. The modification was therefore used to calculate bilirubin concentration in selected nonuremic plasma dialyzates. In six such dialyzates the bilirubin concentration estimated in this way averaged $69 \%$ (range, 62 to $81 \%$ ) of that estimated from the absorbance at 433 to $450 \mathrm{~m} \mu$.

Amino acid estimations were made using a Ninhydrin reagent (12). Serum urea nitrogen levels were estimated on an autoanalyzer. ${ }^{1}$ Hexuronic acid was determined by the method of Dische (13). The other chemical methods were described previously (9).

B. Ultrafiltration. Ultrafiltration of plasma was performed using the technique of Toribara, Terepka, and Dewey (14). Plasma specimens in cellophane casing ${ }^{2}$ were centrifuged for 3 to 4 hours at $2,000 \mathrm{rpm}$ at room temperature, after gassing the apparatus with $5 \% \quad \mathrm{CO}_{2}$ $95 \% \mathrm{~N}_{2}$. Similar results were obtained in several runs performed at $4^{\circ} \mathrm{C}$.

C. Dialysis. Cellophane casing was soaked in distilled water for 1 to 2 days at $20^{\circ} \mathrm{C}$ and then wiped dry and doubly knotted at one end. After introduction of plasma, the other end was also doubly knotted, leaving the tubing lax. The sacs were rinsed thoroughly with distilled water to remove traces of bilirubin from their outer surfaces. When unsoaked fresh casing was used, the resulting pale yellow plasma dialyzates yielded spectral absorption curves characteristic of bilirubin. The derivative azo pigment, however, was brownish-violet instead of violet, although the $\mathrm{OD}$ at 540 to $560 \mathrm{~m} \mu$ was the same as when presoaked casing was used for simultaneous dialysis or ultrafiltration of paired specimens.

The dialysis sacs were placed in Erlenmeyer flasks with phosphate-buffered saline, ${ }^{3}$ and the flasks were gassed with $5 \% \quad \mathrm{CO}_{2}-95 \% \mathrm{~N}_{2}$, stoppered, and covered

1 Technicon Instrument Corp., Chauncey, N. Y.

$219 \mathrm{~mm}$ diameter, purchased from Will Scientific, Inc., Rochester 3, N. Y.

$30.313 \mathrm{~g} \mathrm{KH}_{2} \mathrm{PO}_{4}, 1.093 \mathrm{~g} \mathrm{Na}_{2} \mathrm{HPO}_{4}, 9.00 \mathrm{~g} \mathrm{NaCl}$ per L, $\mathrm{pH} 7.2$. with aluminum foil. Dialysis was carried out at $4^{\circ} \mathrm{C}$ on a mechanical shaker. In subjects with normal renal function plasma specimens of 5 to $7 \mathrm{ml}$ were dialyzed against 5 to $7 \mathrm{ml}$ of dialysis fluid for 21 to 26 hours. This volume relationship was selected in order to heighten dialyzate bilirubin concentration. Optical density measurements were made on the native dialyzates between 350 and $550 \mathrm{~m} \mu$, and on the diazotized fluids between 450 and $700 \mathrm{~m} \mu$, with dialyzates of normal plasma as the blanks. Plasma specimens from subjects with renal failure were dialyzed for 48 hours, and the bilirubin concentrations in these dialyzates were estimated by the diazo method. When plasma specimens were dialyzed against an equal volume of buffer, recovery of bilirubin after 24 to 48 hours averaged $94 \%$ (range, 91 to $101 \%, 5$ studies). When large volumes of buffer were used, recovery of bilirubin after 48 hours averaged $90 \%$ (range, 87 to $94 \%, 5$ studies).

The integrity of the dialysis membranes was confirmed by immunoelectrophoresis (15) of plasma dialyzates, using a potent antiserum to human serum. The method could readily detect human serum albumin at a level of 25 to $50 \mu \mathrm{g}$ per $\mathrm{ml}$. Before immunoelectrophoresis the dialyzates were concentrated fivefold by ultrafiltration through collodion sacs. ${ }^{4}$ Seven 24-hour dialyzates of icteric nonuremic plasma and eight 48-hour dialyzates of icteric uremic plasma were examined. No serum protein constituents were detectable in any of these specimens, indicating that dialyzate albumin concentration was less than 0.015 to $0.03 \%$ of that in the original plasma.

Fresh jaundiced urine was dialyzed on six occasions, and the conjugated bilirubin was found to be $76 \%$ dialyzable through cellophane (range, 66 to 83\%) after 48 hours.

D. Ultracentrifugation. Ultracentrifugation of urine, urine and plasma dialyzates, and plasma ultrafiltrates was usually carried out for 16 to 18 hours, and in one instance for 63 hours, at $80,000 \times g$ in a Spinco model $\mathrm{L}$ ultracentrifuge using an angle rotor. Several ultracentrifugations were also performed in a swinging bucket rotor for 60 to 65 hours at $100,000 \times g$.

E. Electrophoresis. Filter paper electrophoresis of plasma and urine was performed in an aluminum foilcovered Beckman-Spinco model $\mathrm{R}$ electrophoretic apparatus using Whatman $3 \mathrm{MM}$ paper. The use of thick filter paper permitted the application of 150 to 300 $\mu 1$ of serum or plasma to each strip. Electrophoresis was performed in either barbital $(\Gamma / 20.075, \mathrm{pH} 8.6)$, phosphate $(\Gamma / 20.075, \mathrm{pH} 7.4)$, or Tris-maleate $(\mathrm{pH} 8.6)$ (16) buffer at $4 \mathrm{v}$ per $\mathrm{cm}$. After a 16-hour run the paper strips were dried for 60 to 90 minutes in a desiccator, which was evacuated to $1 \mathrm{~mm} \mathrm{Hg}$ and protected from light. The strips were stained for protein with bromphenol blue or buffalo blue-black and for bilirubin by both diazotization and oxidative conversion to biliverdin. The respective bilirubin staining baths consisted of $a$ )

\footnotetext{
4 Carl Schleicher \& Schuell, Keene, N. H.
} 


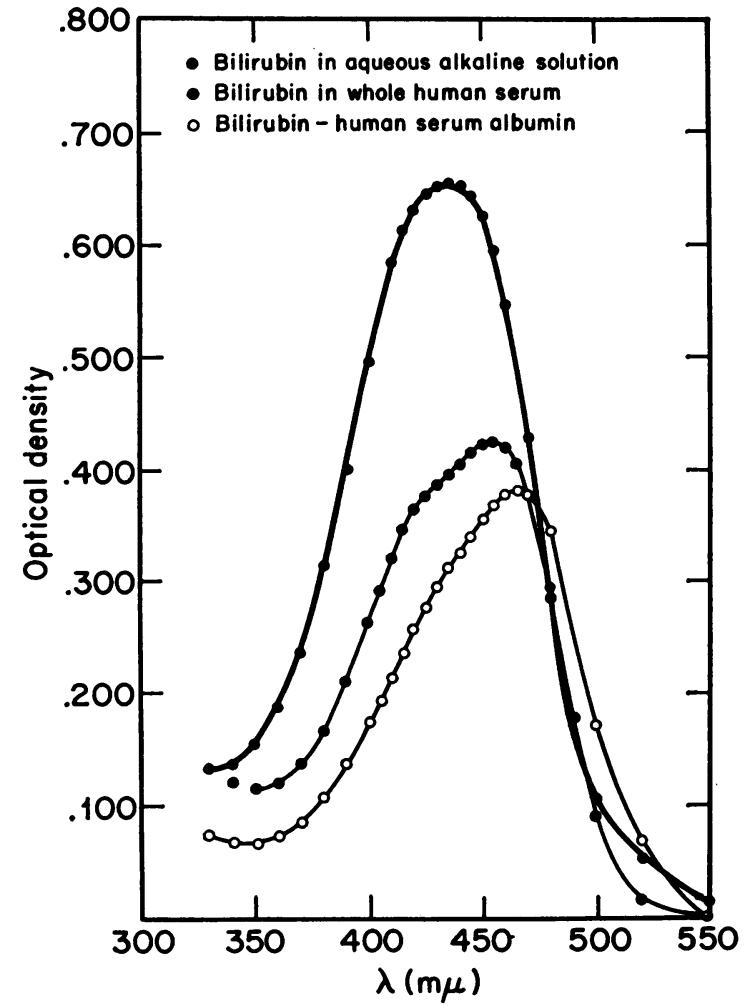

Fig. 1. BILIRUBIN ABSORPTION SPECTRA. -bilirubin in aqueous solution, $10 \mu \mathrm{g} / \mathrm{ml}, \mathrm{pH} 8.5$ phosphate buffer; $\odot$-bilirubin added to normal human serum, $6.5 \mu \mathrm{g} / \mathrm{ml}$; $\mathrm{O}$-unconjugated bilirubin-serum albumin complex eluted from paper electrophoretic strip (barbital buffer, $\Gamma / 2$ $0.075, \mathrm{pH} 8.6,16$ hours, $3 \mathrm{v}$ per $\mathrm{cm}$ ).

1 part of diazotized sulfanilic acid and 2 parts of $50 \%$ methanol and b) $100 \mathrm{mg}$ per $100 \mathrm{ml} \mathrm{FeCl}$ in $3 \%$ trichloroacetic acid (modified Fouchet reagent). Plasma strips were removed from the diazo bath within 15 to 20 seconds and urine strips within 5 seconds, longer intervals being associated with progressive elution of pigment from the paper. The derivative azo pigment was usually reddish-violet because of the neutral or alkaline buffers used for the electrophoresis. The colors were stable for months when the strips were protected from light. A band was considered to contain bilirubin when it was yellow and yielded both a reddish-violet azo derivative and biliverdin with the appropriate reagents. Electrophoresis was also performed using blocks of polyvinyl chloride, 5 at $4^{\circ} \mathrm{C}$.

\section{Results}

\section{A. Spectral absorption of bilirubin solutions}

Figure 1 shows reference bilirubin spectral absorption curves for comparison with the curves of

5 B. F. Goodrich, Geon no. 427. plasma dialyzates and ultrafiltrates. Bilirubin in aqueous solution at $\mathrm{pH} 8.5$ had a peak absorption at $435 \mathrm{~m} \mu$. The absorption maximum shifted to 460 to $465 \mathrm{~m} \mu$ in the presence of human serum albumin (Figure 1), and the spectrum was similar to the one obtained when bilirubin was added to normal whole serum.

\section{B. Dialysis and ultrafiltration experiments}

Dialysis of plasma specimens from both humans and dogs with conjugated hyperbilirubinemia consistently yielded pale yellow dialyzates that had absorption spectra characteristic of bilirubin when read against the colorless dialyzate of normal human plasma as the blank (Figure 2, A and B). The absorption maxima fell between 433 and $450 \mathrm{~m} \mu$. The dialyzable yellow pigment yielded a violet azo derivative with maximal absorption at 540 to $560 \mathrm{~m} \mu$, which is characteristic of azobilirubin (Figure 3).

As is typical of conjugated bilirubin, the dialyzate yellow pigment was not extractable with chloroform, and methanol was not necessary for color development in the diazo reaction. Specimens of normal dog and human plasma to which bilirubin ${ }^{6}$ had been added in concentrations of either 6 , or 30 to $40 \mathrm{mg}$ per $100 \mathrm{ml}$, yielded no dialyzable bilirubin. The dialyzates of such unconjugated hyperbilirubinemic human plasma were very faintly yellow, however, when the plasma level was $40 \mathrm{mg}$ per $100 \mathrm{ml}$ or higher. These exhibited an absorption maximum at 390 to 400 $\mathrm{m} \mu$ (Figure 2B) and did not yield azobilirubin on diazotization. Bilirubin was not dialyzable from a specimen of bloody inflammatory human synovial fluid in which the bilirubin concentration was $10 \mathrm{mg}$ per $100 \mathrm{ml}$ (all unconjugated).

The dialyzable fraction of plasma bilirubin in patients with conjugated hyperbilirubinemia and normal renal function, together with concurrent renal clearance values for some of the patients, is given in Table I. Similar studies in five jaundiced dogs are shown in Table II. The proportion of plasma bilirubin that dialyzed in vitro $(0.7 \%)$ in the patients in whom clearance studies were performed was similar to the proportion of plasma bilirubin that was cleared by their kidneys

${ }^{6}$ Fisher Scientific Company, New York, N. Y. 

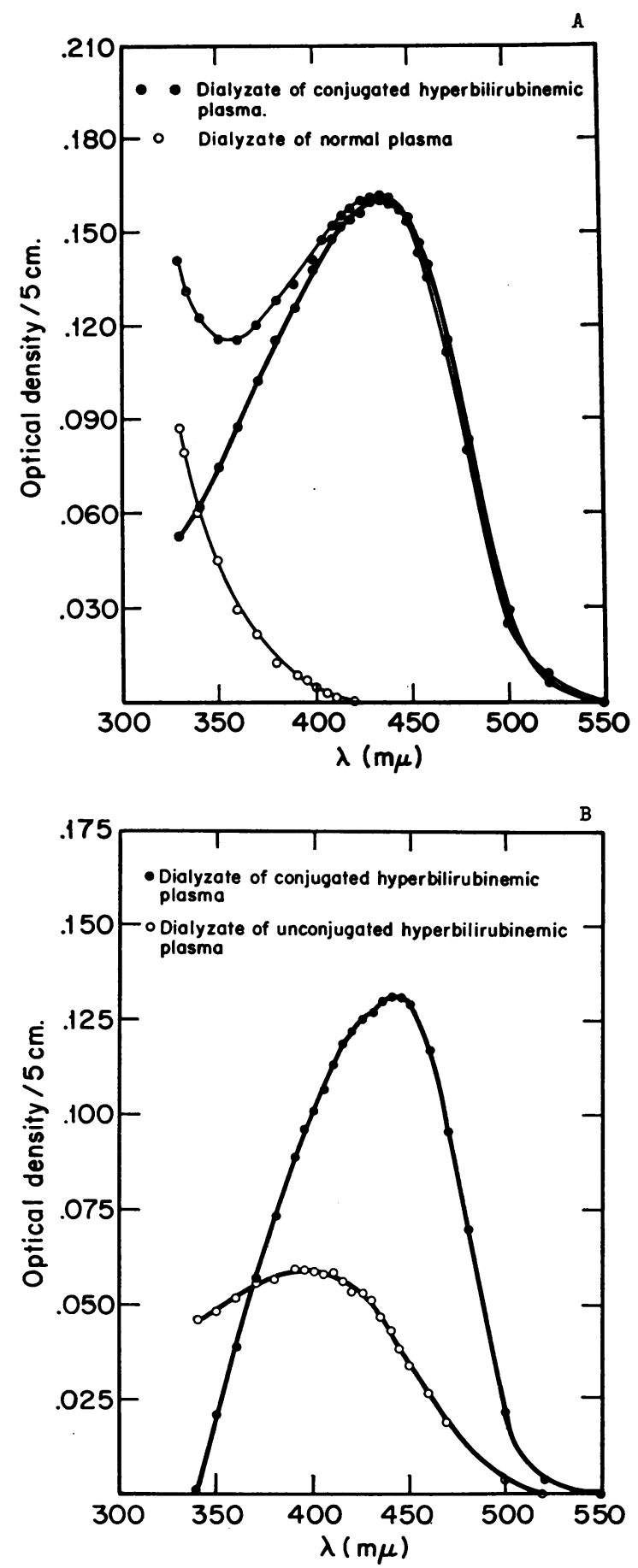

Fig. 2 A. Absorption spectra of dialyzable plasma CONJUGATED BILIRUBIN. 23-hour concurrent dialyses of jaundiced human plasma ( $\mathrm{Le}$, plasma bilirubin, $30.7 \mathrm{mg}$ per $100 \mathrm{ml}$ ) and normal human plasma. Jaundiced plasma dialyzate read against buffered saline $(\odot)$ and against the dialyzate of normal plasma (๑). B. ABsorption SPECTRA OF DIALYZATES OF CONJUGATED AND UNCONJU-

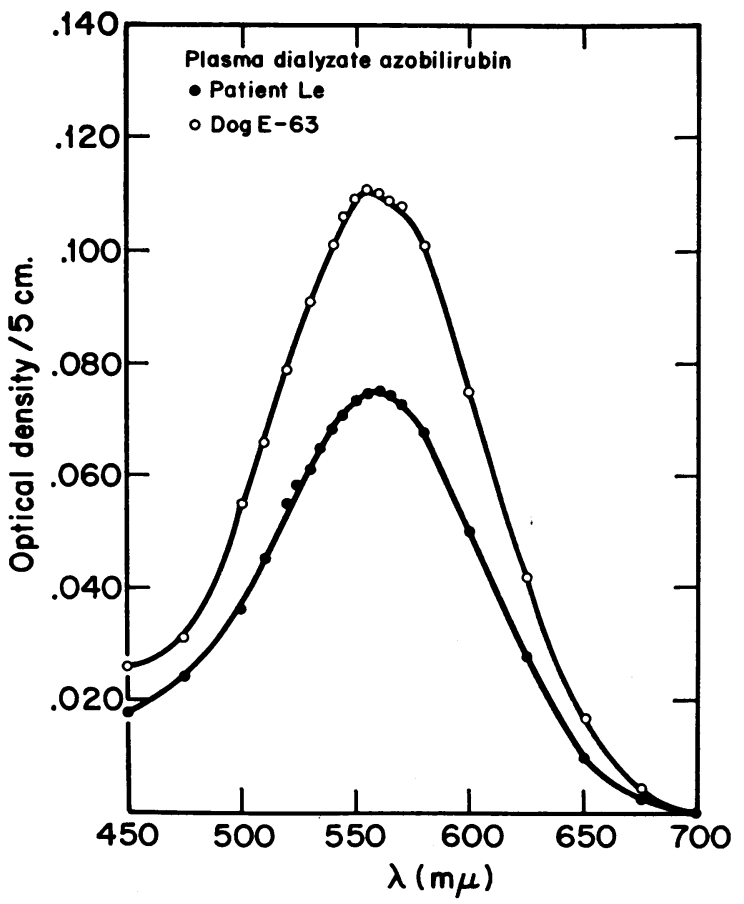

Fig. 3. ABSORPtion SPECTRA OF AZOBILIRUBIN FROM PLASMa dialyzates. 23-hour dialyzate of jaundiced human plasma (Le, plasma bilirubin, $30.7 \mathrm{mg}$ per $100 \mathrm{ml}$ ) and 22-hour dialyzate of jaundiced dog plasma (E, plasma bilirubin, $8.1 \mathrm{mg}$ per $100 \mathrm{ml}$ ). Diazo reaction performed with 1 vol dialyzate plus 1 vol reagent.

$(0.5 \%)$. These values for the dogs were $1.6 \%$ and $1.3 \%$, respectively.

A striking finding was that the dialyzable fraction of plasma bilirubin was elevated in patients who developed renal failure. The percentage of plasma bilirubin that was dialyzable increased with advancing renal failure in each of the 10 patients studied (Figure 4). This also occurred in two jaundiced dogs after bilateral ureteral ligation.

The dialyzable plasma fraction did not appear to be free conjugated bilirubin that was in equilibrium with the much larger fraction of nondialyzable bilirubin. Serial dialyses of jaundiced plasma yielded progressively decreasing concentrations of dialyzable bilirubin (Figure 5). Serial dialyses were performed on plasma from nine jaundiced patients (seven of them uremic) and

GATED HYPERBILIRUBINEMIC PLASMA. 20-hour concurrent dialyses of jaundiced human plasma ( $\mathrm{Mi}$, plasma bilirubin, $18.1 \mathrm{mg}$ per $100 \mathrm{ml}, 5^{\prime}$ fraction, $85 \%$ of total) and normal human plasma with added bilirubin ( $40.5 \mathrm{mg}$ per $100 \mathrm{ml}$ ). 
TABLE I

Dialyzable plasma bilirubin in jaundiced patients with normal renal function*

\begin{tabular}{|c|c|c|c|c|c|c|c|}
\hline \multirow[b]{2}{*}{ Patient } & \multirow[b]{2}{*}{ Diagnosis } & \multicolumn{2}{|c|}{ Plasma bilirubin } & & & \multirow[b]{2}{*}{$\mathrm{C}_{\mathrm{Cr}}$} & \multirow[b]{2}{*}{$\mathrm{C}_{\mathrm{B}} / \mathrm{C}_{\mathrm{Cr}}$} \\
\hline & & Total & Conjugated $\dagger$ & \multicolumn{2}{|c|}{ Dialyzable bilirubin } & & \\
\hline & & $m g / 100 \mathrm{ml}$ & $\%$ of total & $\mu g / m l$ & $\%$ of total & $m l / m i n$ & $\%$ \\
\hline $\mathrm{Cl}$ & Carcinoma of pancreas & 25.7 & 85 & 2.1 & 0.8 & & \\
\hline \multirow[t]{2}{*}{$\mathrm{Sa}$} & Carcinoma of gall bladder & 27.0 & 83 & 1.1 & 0.4 & & \\
\hline & & 29.5 & (87) & 1.3 & 0.5 & & \\
\hline Sh & Carcinoma of gall bladder & 16.8 & (87) & 0.7 & 0.4 & & \\
\hline $\mathrm{Li}$ & Nutritional cirrhosis, fatty liver & 33.3 & 83 & 1.5 & 0.9 & & \\
\hline Ty & Carcinoma of pancreas & 36.4 & (86) & 1.6 & 0.4 & & \\
\hline $\mathrm{Le}$ & Carcinoma of pancreas & 30.7 & (86) & 1.0 & 0.3 & & \\
\hline \multirow[t]{2}{*}{$\mathrm{Na}$} & Infectious hepatitis & 12.7 & 83 & 0.4 & 0.3 & & \\
\hline & & 13.4 & 85 & 0.7 & 0.5 & & \\
\hline $\mathrm{Fa}$ & Infectious hepatitis & 11.4 & 81 & 0.5 & 0.4 & & \\
\hline Ho & Cholestatic jaundice & 16.1 & 78 & 0.6 & 0.3 & & \\
\hline $\mathrm{Be}$ & Infectious hepatitis & 20.6 & 79 & 0.8 & 0.4 & & \\
\hline $\mathrm{Mi}$ & Cholestatic jaundice & 18.1 & (85) & 0.8 & 0.4 & & \\
\hline $\mathrm{Ra}$ & Carcinoma of pancreas & 29.1 & 83 & 2.7 & 0.9 & 68.4 & 0.8 \\
\hline Sy & Nutritional cirrhosis, fatty liver & 32.4 & 83 & 3.2 & 1.0 & 68.5 & 0.8 \\
\hline $\mathrm{Ca}$ & Homologous serum jaundice & 18.6 & 81 & 1.1 & 0.6 & 76.1 & 0.3 \\
\hline $\mathrm{Si}$ & Choledocholithiasis & 8.8 & 76 & 0.6 & 0.7 & 98.5 & 0.4 \\
\hline $\mathrm{Bu}$ & Postnecrotic cirrhosis & 25.2 & 77 & 2.0 & 0.8 & 81.6 & 0.6 \\
\hline $\mathrm{Cr}$ & Infectious hepatitis & 32.2 & (82) & 1.4 & 0.4 & 102.8 & 0.3 \\
\hline \multicolumn{2}{|c|}{ Average } & & & & $\begin{array}{l}0.7 \ddagger \\
0.6 \$\end{array}$ & & 0.5 \\
\hline
\end{tabular}

* Five- to seven-ml plasma specimens were dialyzed against an equal volume of phosphate buffered saline in an aluminum foil-covered flask for about 24 hours at $4^{\circ} \mathrm{C}$. Dialyzate bilirubin concentration was estimated from the peak OD in the range 433 to $450 \mathrm{~m} \mu$. $C_{\mathrm{Cr}_{\mathrm{r}}}=$ creatinine clearance; $\mathrm{C}_{\mathrm{B}}=$ bilirubin clearance.

$\dagger$ Estimated by the method of Weber and Schalm (10), except for the figures in parentheses, which refer to the 5 -minute direct-reacting plasma fraction.

$\ddagger$ Includes only the last six patients, for whom $\mathrm{C}_{\mathrm{B}} / \mathrm{C}_{\mathrm{Cr}_{\mathbf{r}}}$ values are also given.

$\$$ Includes all values in the table.

from two jaundiced uremic dogs. Five $\mathrm{ml}$ plasma was dialyzed for successive 24-hour periods against 50 - to $100-\mathrm{ml}$ portions of buffered saline. Bilirubin levels in the dialyzates were negligible after the second or third 24-hour period, even though 70 to $80 \%$ of the original bilirubin was still recoverable from the sacs. The amount of bilirubin dialyzable from nonuremic plasma was between 1 and $2 \%$ of the total, and from

TABLE II

Dialyzable plasma bilirubin in jaundiced dogs with normal renal function*

\begin{tabular}{cccccc}
\hline \hline Dog & $\begin{array}{c}\text { Plasma } \\
\text { bilirubin }\end{array}$ & Dialyzable bilirubin & GFR & $\mathrm{C}_{\mathrm{B}} / \mathrm{GFR}$ \\
\hline & $m g / 100 \mathrm{ml}$ & $\mu g / m l$ & $\%$ & $\mathrm{ml} / \mathrm{min}$ & $\%$ \\
$\mathrm{~A}$ & 4.3 & 0.8 & 1.8 & $29.4 \dagger$ & 1.7 \\
$\mathrm{~B}$ & 3.4 & 0.5 & 1.5 & 77.2 & 1.3 \\
$\mathrm{C}$ & 2.3 & 0.3 & 1.5 & 64.1 & 0.9 \\
$\mathrm{D}$ & 4.3 & 0.7 & 1.6 & 41.8 & 1.6 \\
& 4.8 & 0.7 & 1.4 & 42.4 & 1.2 \\
E & 8.1 & 1.5 & 1.8 & $51.5 \dagger$ & 1.0 \\
Average & & & 1.6 & & 1.3
\end{tabular}

* The conditions of plasma dialysis were as given in Table I. Glomerular filtration rate (GFR) was estimated by creatinine clearance except in dog $E$, where inulin clearance was used.

$t$ Ureteral urine collection from one kidney. uremic plasma as high as $11 \%$ when these large dialyzate volumes were used. Uremic specimens that had yielded dialyzable fractions ${ }^{7}$ of 1.8 and $2.3 \%$ when dialyzed against equal volumes of buffer, yielded 8 and $11 \%$ when dialyzed against large volumes. The total recoveries of bilirubin in the latter two instances were 78 and $86 \%$. When even larger volumes of dialyzate were used (e.g., $1 \mathrm{ml}$ plasma against 100 to $250 \mathrm{ml}$ buffer), virtually all of the dialyzable bilirubin could be removed from the sac within 24 hours. The method for estimation of bilirubin would not detect concentrations below $0.03 \mu \mathrm{g}$ per $\mathrm{ml}$, and it remains possible that a minute fraction of plasma conjugated bilirubin may be unbound and in free equilibrium with protein-bound bilirubin.

Plasma ultrafiltrates from humans and dogs with conjugated hyperbilirubinemia were faintly yellow. Like the dialyzates, the ultrafiltrates yielded violet azo derivatives with absorption maxima at 540 to $560 \mathrm{~m} \mu$, indicating that the yel-

${ }^{7}$ Calculated assuming equilibrium between dialyzate and sac contents. 
low pigment was bilirubin. The spectra of the native ultrafiltrates, however, were not typical of bilirubin, usually exhibiting absorption maxima in the 410- to $425-\mathrm{m} \mu$ range (Figure 6). The uremic plasma ultrafiltrate absorption spectrum shown in Figure 7 differed from the others in that the peak OD was at $438 \mathrm{~m} \mu$. Figures 6 and 7 also show that more plasma bilirubin was dialyzable than was ultrafilterable.

\section{Ultracentrifugation experiments}

Ultracentrifugation of human and canine jaundiced urine produced a gradient of yellow color from the top to the bottom of the centrifuge tubes using either angle or bucket rotors. A comparable gradient of violet azopigment was found after diazotization of appropriate samples, indicating that conjugated bilirubin had undergone sedimentation during ultracentrifugation. Ultracentrifugations of dialyzates of jaundiced urine, dialyzates of jaundiced uremic plasma, and ultrafiltrates of jaundiced uremic plasma were also performed. A gradient of conjugated bilirubin was produced in each specimen. Data from a representative experiment are given in Table III. Five $\mathrm{ml}$ of dialyzates of jaundiced uremic dog

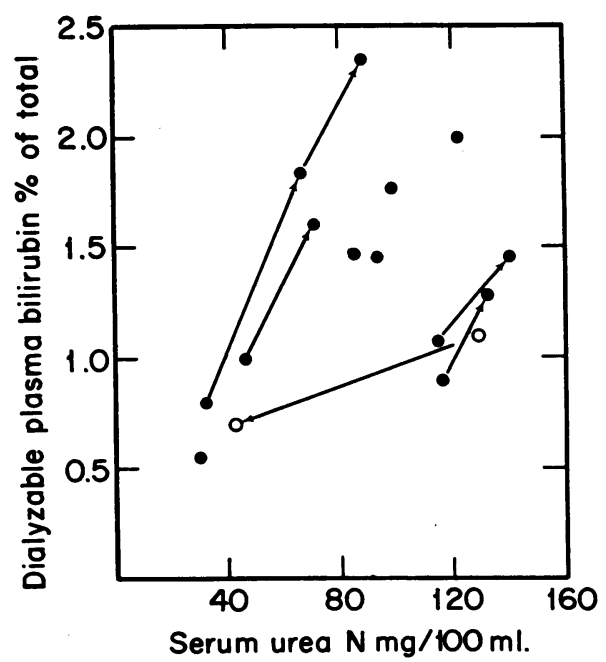

Fig. 4. Dialyzable plasma conjugated bilirubin in JAUNDICED PATIENTS WITH RENAL FAILURE. 48-hour plasma dialyzates. Connected points refer to serial studies in individual patients. Connected open circles refer to studies before and after hemodialysis in a patient with fulminant hepatitis. Dialyzate bilirubin estimated by diazo reaction.

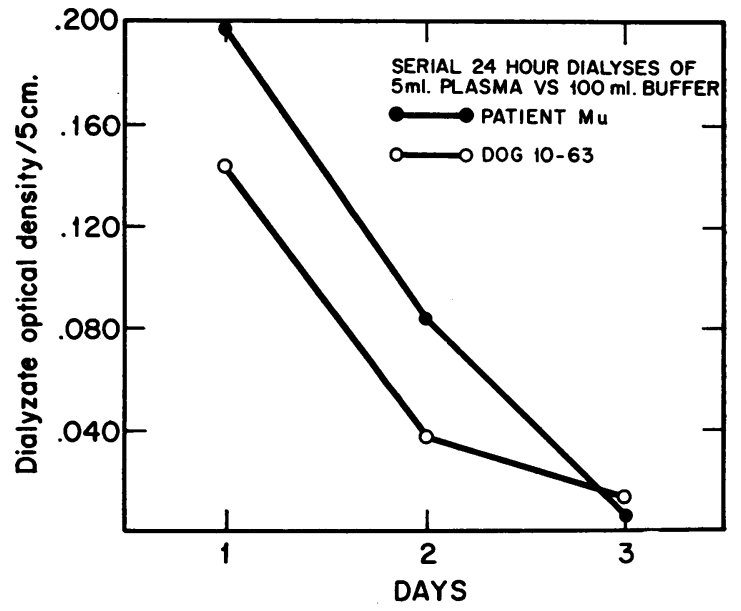

Fig. 5. Serial dialyses of Jaundiced plasma. 24hour dialyses of $5 \mathrm{ml}$ plasma from jaundiced patient ( $\mathrm{Mu}$, plasma bilirubin, $27.7 \mathrm{mg}$ per $100 \mathrm{ml}$, serum urea $\mathrm{N}, 99 \mathrm{mg}$ per $100 \mathrm{ml}$ ) and jaundiced dog (10-63, plasma bilirubin, $11.1 \mathrm{mg}$ per $100 \mathrm{ml}$, serum urea $\mathrm{N}, 126 \mathrm{mg}$ per $100 \mathrm{ml}$ ), each vs. $100 \mathrm{ml}$ buffered saline. Dialysis fluid changed daily; OD $450 \mathrm{~m} \mu$.

plasma, jaundiced uremic human plasma, and jaundiced human urine were centrifuged at $80,000 \times g$ for 63 hours. The following determinations were then performed on the top and bottom $1 \mathrm{ml}$ of each dialyzate: $a$ ) $\mathrm{OD}$ at $435 \mathrm{~m} \mu, b$ ) Folin-Ciocalteau reaction for protein, and $c$ ) Ninhydrin reaction after hydrolysis at $105^{\circ} \mathrm{C}$ for 16 hours with $6 \mathrm{~N} \mathrm{HCl}$. The results are tabulated as optical densities. Each dialyzate exhibited a bilirubin gradient and a gradient of Folin-reactive material, suggesting that dialyzable polypeptides of low molecular weights were present in the fluids. Both the gradient and increase in amount of Ninhydrin-reactive material after hydrolysis supported that inference. A gradient of hexuronic acid was also found in other runs in which this analysis was performed. Pure bilirubin in aqueous alkaline solution at concentrations comparable to those in the dialyzates did not sediment on ultracentrifugation. These results suggested that urinary conjugated bilirubin and plasma dialyzable bilirubin were bound to a "carrier" whose molecular weight was high enough to permit sedimentation of the bilirubin-carrier complex during ultracentrifugation. In the case of dialyzates of nonuremic jaundiced plasma it was difficult to evaluate the optical density differences because of the low initial optical density 


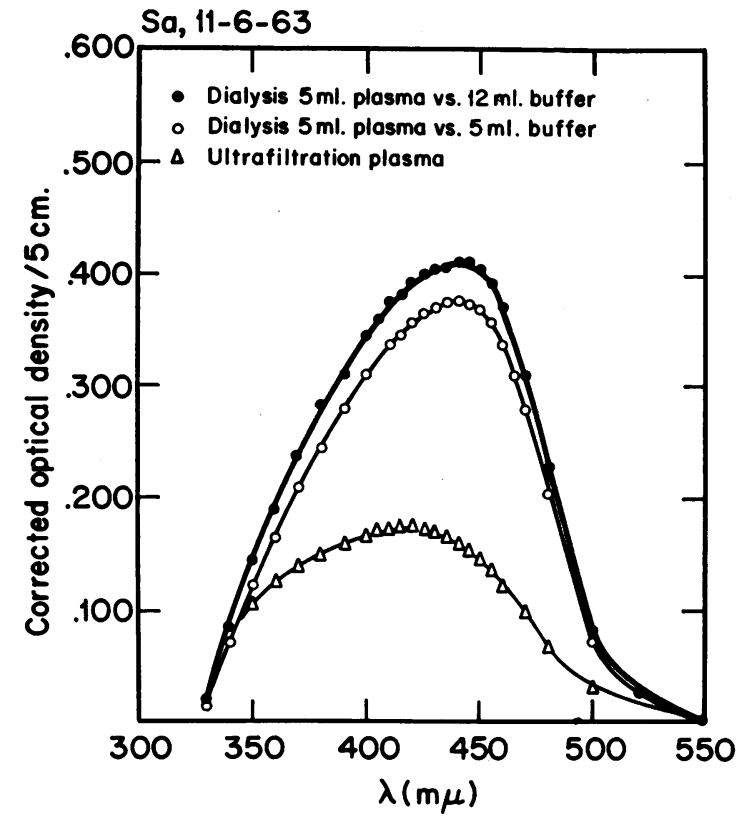

Fig. 6. Absorption SPECtra of dialyzates AND ULTRAFILTRATE OF JAUNDICED PLASMA. Plasma from patient Sa, bilirubin, $27.0 \mathrm{mg}$ per $100 \mathrm{ml}$. 21-hour dialyses and 3-hour Toribara ultrafiltration. Specimens read against comparable dialyzates and ultrafiltrate of normal human plasma. Dialyzate optical densities were multiplied by the factor (volume of dialyzate + plasma)/(volume of plasma) so that the plotted values are proportional to total dialyzable and ultrafilterable bilirubin, respectively.

and the fading that occurred during prolonged ultracentrifugation.

\section{Ammonium sulfate precipitation}

The addition of ammonium sulfate to jaundiced whole urine, urine dialyzates, and dialyzates of uremic jaundiced plasma, in amounts sufficient to yield $80 \%$ saturation, caused precipitation of almost all of the bilirubin. Filtration through a $5-\mu$ Millipore filter ${ }^{8}$ yielded faintly colored filtrates, while the bilirubin was retained on the filter. The precipitated bilirubin dissolved readily in water or $0.15 \mathrm{M} \mathrm{NaCl}$, and it exhibited the same absorption spectrum and electrophoretic and staining properties as in native jaundiced urine. When these precipitates of conjugated bilirubin were dissolved in a very small volume of water, the bilirubin concentration was increased many

\footnotetext{
8 Millipore Filter Corp., Bedford, Mass.
}

times over that in the native dialyzates. These concentrated solutions were used for electrophoretic studies.

\section{E. Electrophoretic experiments}

Plasma bilirubin electrophoretic patterns were qualitatively similar on filter paper at both $\mathrm{pH}$ 8.6 (barbital or Tris-maleate buffer) and 7.4 (phosphate buffer). In the concurrent electrophoreses depicted in Figures 9 and 11, the specimen volumes had been adjusted so that equal amounts of bilirubin (i.e., diazotizable pigment) were applied to each strip.

1. Human studies. Electrophoresis of sera obtained from patients with unconjugated hyperbilirubinemia showed that bilirubin migrated only with albumin. When pure bilirubin was added to normal plasma in concentrations up to $40 \mathrm{mg}$ per $100 \mathrm{ml}$, bilirubin migration was similarly limited to the albumin zone.

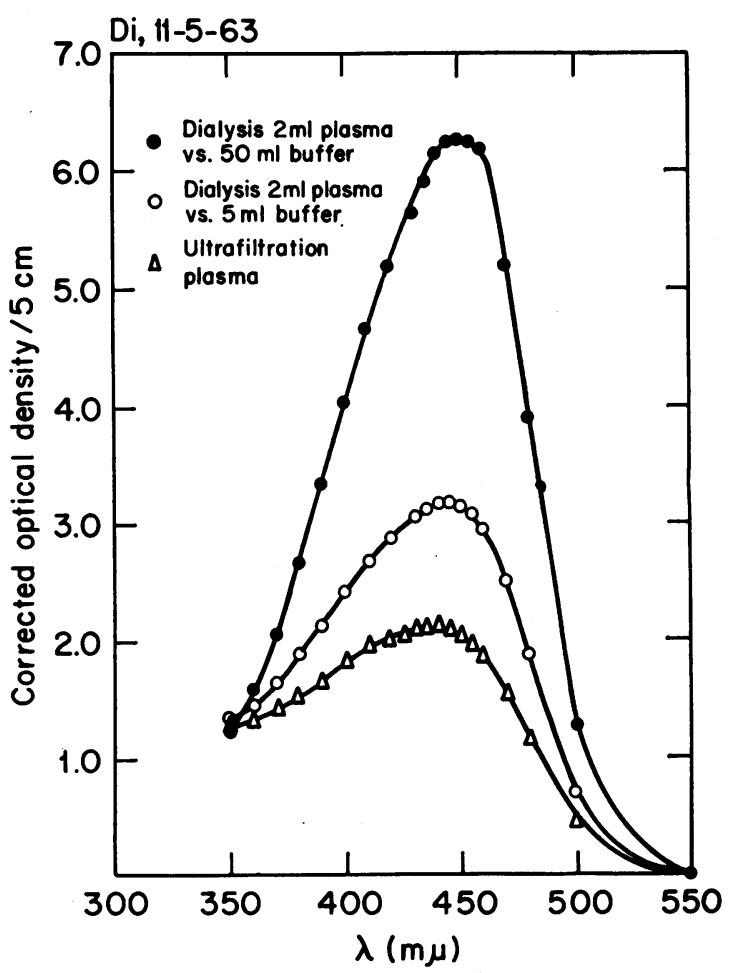

Fig. 7. Absorption spectra of dialyzates aNd UlTRAFIlTRATE OF UREMIC JAUNDICED Plasma. Plasma from patient $\mathrm{Di}$, bilirubin, $34.1 \mathrm{mg}$ per $100 \mathrm{ml}$, serum urea $\mathrm{N}$, $85 \mathrm{mg}$ per $100 \mathrm{ml}$. 30-hour dialyses and 3-hour Toribara ultrafiltration. Dialyzate OD corrected as in Figure 6. 


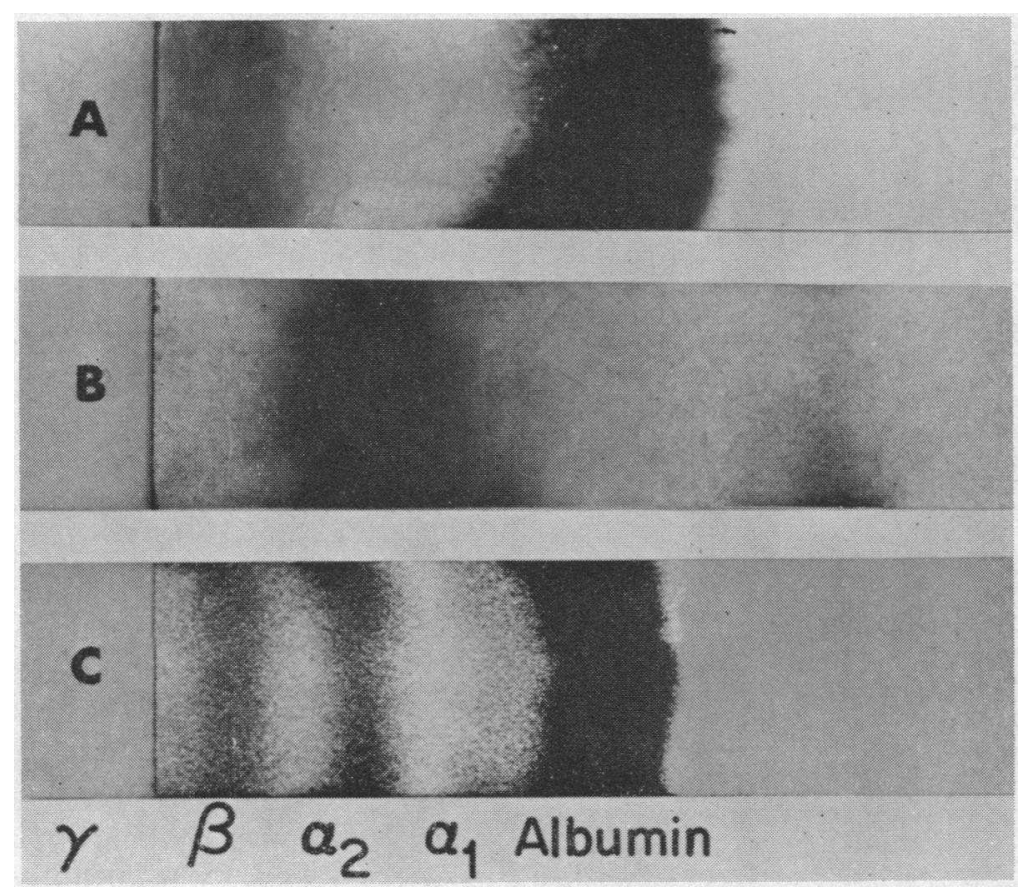

Fig. 8. Electrophoretic PATterns OF SERUM AND URINE CONJUGATED BILIRUbin. A. Serum from patient Ty, plasma bilirubin, $36.4 \mathrm{mg}$ per 100 $\mathrm{ml}$, showing bilirubin in the albumin and beta globulin zones. B. Urine from the same patient showing bilirubin in the alpha and beta globulin zones and nonbilirubin diazotizable material in the prealbumin zone. $\mathrm{C}$. Reference serum protein pattern. Barbital buffer, $\mathrm{pH}$ 8.6. Diazo staining of $\mathrm{A}$ and $\mathrm{B}$; bromphenol blue staining of $\mathrm{C}$.

Specimens of serum and plasma obtained from 13 patients with extrahepatic obstructive jaundice, whose total plasma bilirubin levels were at least $15 \mathrm{mg}$ per $100 \mathrm{ml}$, consistently disclosed migration of a small fraction of bilirubin in the beta globulin zone. (Figures 8A and 9A). Specimens obtained from cirrhotic patients with normal renal function and comparable elevations of plasma conjugated bilirubin showed a less pronounced "beta-bilirubin" zone. The spectrum of

TABLE III

Ultracentrifugation gradients in dialyzates of jaundiced plasma and urine*

\begin{tabular}{|c|c|c|c|c|}
\hline \multirow[b]{2}{*}{ Specimen } & \multirow[b]{2}{*}{ Bilirubin } & \multirow[b]{2}{*}{ Folin reaction } & \multicolumn{2}{|c|}{ Ninhydrin reaction } \\
\hline & & & $\begin{array}{c}\text { Before } \\
\text { hydrolysis }\end{array}$ & $\begin{array}{c}\text { After } \\
\text { hydrolysis }\end{array}$ \\
\hline & $O D 435 m \mu$ & $O D 700 m \mu$ & \multicolumn{2}{|c|}{$O D 570 \mathrm{m \mu}_{\mu}$} \\
\hline $\begin{array}{l}\text { Dog plasma dialyzate } \\
\text { Top }\end{array}$ & 0.068 & 0.048 & & 88 \\
\hline Bottom & 0.150 & 0.102 & 0.138 & 10.4 \\
\hline \multicolumn{5}{|l|}{ Human plasma dialyzate } \\
\hline Top & 0.093 & 0.056 & & 5.6 \\
\hline \multirow{2}{*}{\multicolumn{5}{|c|}{ Human urine dialyzate }} \\
\hline & & & & \\
\hline Top & 2.44 & 0.478 & & 29.6 \\
\hline Bottom & 5.15 & 0.600 & 1.28 & 42.0 \\
\hline
\end{tabular}

* Five ml of dialyzates of uremic jaundiced dog plasma, uremic jaundiced human plasma, and jaundiced human urine were ultracentrifuged for 63 hours at $80,000 \times g$. Optical density values are given for the top and bottom milliliter
(approximate) in each specimen. Each tube exhibited a visible gradient of yellow color at the end of the ultracentrifugation. 

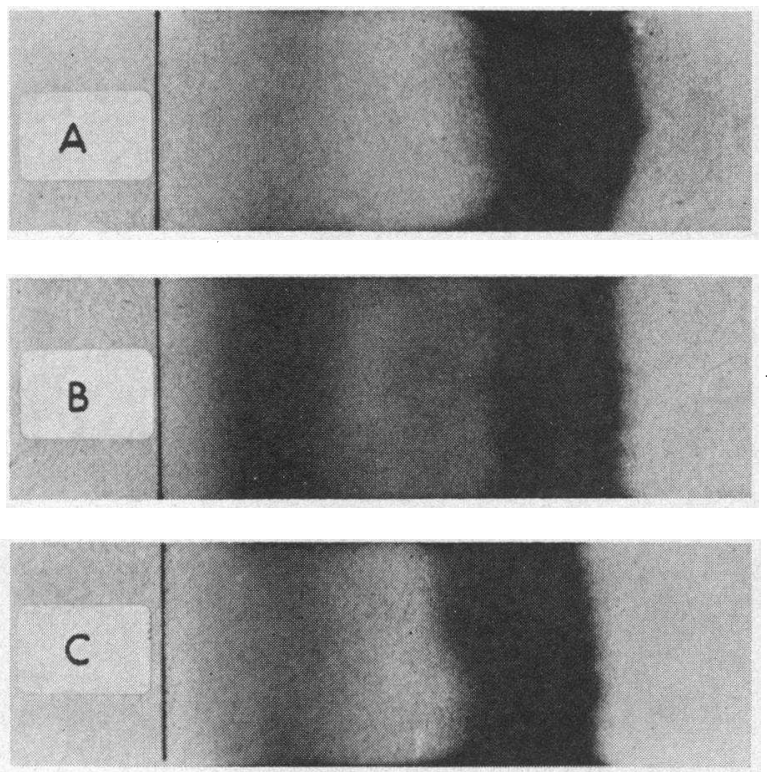

Fig. 9. Electrophoretic patterns of plasma conJUGATED BILIRUBIN BEFORE AND AFTER UREMIA. Plasma from patient $\mathrm{Co}$, plasma bilirubin, $32.9 \mathrm{mg}$ per $100 \mathrm{ml}$. A. Preuremia. B. Serum urea N, $122 \mathrm{mg}$ per $100 \mathrm{ml}$. C. Uremic plasma (B) after 48 hours of dialysis against buffered saline. Tris buffer, $\mathrm{pH}$ 8.6. Diazo staining.

the yellow pigment eluted from the beta globulin zone could not be characterized because the eluates were opalescent. Elution of this zone with diazotized sulfanilic acid, however, yielded a violet pigment with the spectral absorption characteristics of azobilirubin. Staining of the paper strips with diazo reagent and with Fouchet reagent yielded typical bilirubin derivatives in both the albumin and beta globulin zones.

Paper electrophoresis of urine obtained from each of eight patients with obstructive jaundice disclosed three zones of yellow diazotizable pigment. Their mobilities corresponded with beta and alpha globulins and prealbumin (Figure 8B), although it was not possible to detect protein in any of these zones with either bromphenol blue or buffalo blue-black. The prealbumin pigment zone was also present in normal urine, and in both jaundiced and normal urine its derivative azopigment was orange rather than violet, suggesting that it was not bilirubin. The mobility of urinary conjugated bilirubin on paper therefore corresponded with the beta and alpha globulin zones. The relative proportions were variable, and there was usually no sharp demarcation between the alpha and beta zones.

Plasma electrophoretic studies were performed in two patients with extrahepatic obstructive jaundice before and after they developed renal failure. The uremic specimens showed an increased proportion of total plasma bilirubin in the beta globulin zone, and some appeared in the alpha globulin zone (Figure 9B). Dialysis of these uremic jaundiced plasma specimens caused a decrease of bilirubin in the beta globulin zone (and probably the alpha also) (Figure 9C). In two other jaundiced patients in whom preuremia specimens were not available, it was also possible to demonstrate very prominent "beta- and alphabilirubin" zones in the uremic plasma specimens and a decrease in the intensity of those zones after in vitro dialysis of plasma. The diazotized beta globulin zone pigment in several of these uremic plasma specimens was eluted from both paper strips and polyvinyl chloride and was found to have an absorption spectrum characteristic of azobilirubin. Paper electrophoresis of jaundiced uremic plasma dialyzates in which the bilirubin had first been concentrated by ammonium sulfate precipitation disclosed bilirubin migration in the beta-alpha globulin zone. This was similar to the migration of bilirubin in native jaundiced urine and urine dialyzates, as well as in these fluids after concentration by ammonium sulfate precipitation.

On polyvinyl chloride at $\mathrm{pH} 7.4$ (phosphate buffer) the pattern of plasma conjugated bilirubin migration was similar to its pattern on paper electrophoresis. The pattern in uremic jaundiced plasma was also similar to that on paper, except that a faint prealbumin bilirubin zone was also discernible. Electrophoresis of jaundiced urine and urine dialyzates on polyvinyl chloride showed migration of most of the bilirubin in the prealbumin zone, with broad trailing back to the origin. Analysis for Folin-reactive material disclosed several peaks, one of which coincided with the prealbumin peak of bilirubin concentration. The bilirubin concentration in native dialyzates of jaundiced plasma was too low to permit satisfactory electrophoresis. Electrophoresis of uremic jaundiced plasma dialyzates in which the bilirubin had been first concentrated by ammonium sulfate precipitation disclosed a bilirubin migration pat- 


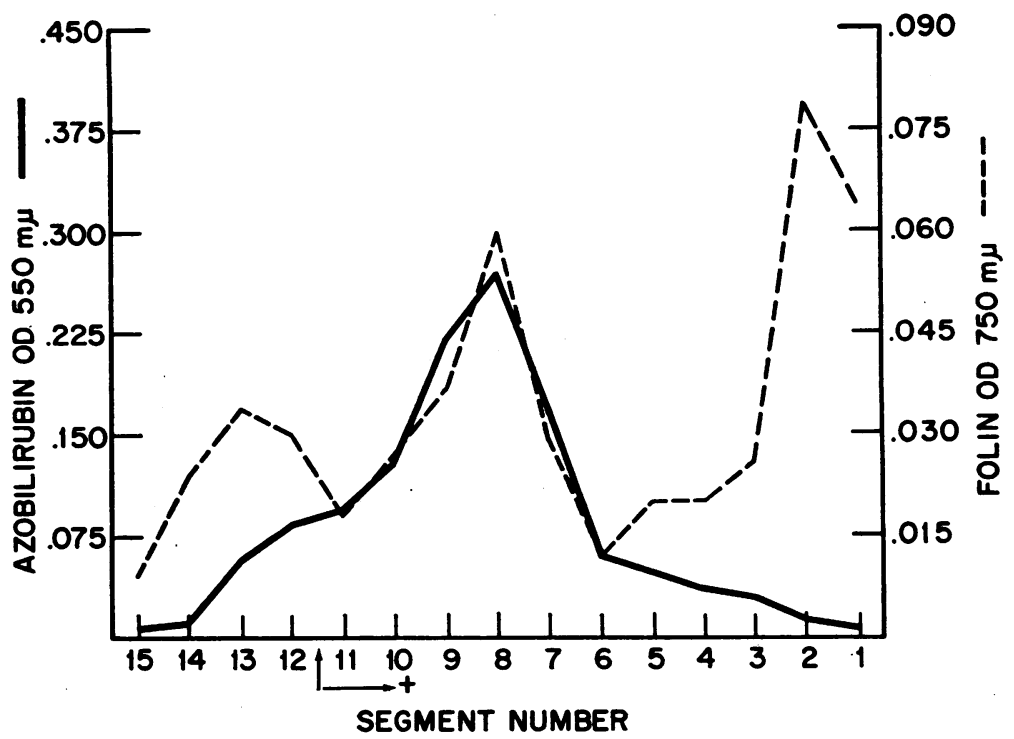

Fig. 10. Polyvinyl chloride electrophoresis of dialyzate of JaUnDiCED UREMIC PLASMA. $72 \mathrm{ml}$ plasma (patient Cs, bilirubin, $27.3 \mathrm{mg}$ per $100 \mathrm{ml}$, serum urea $\mathrm{N}, 154 \mathrm{mg}$ per $100 \mathrm{ml}$ ) dialyzed for 66 hours vs. 150 $\mathrm{ml}$ buffered saline. Dialyzate conjugated bilirubin precipitated with $80 \%$ saturated ammonium sulfate, filtered, and redissolved in $2 \mathrm{ml}$ water. Block segments eluted with buffered saline. Origin at vertical arrow. Phosphate buffer, $\Gamma / 2.075, \mathrm{pH} 7.4,4$ hours, $20 \mathrm{v}$ per $\mathrm{cm}$.

tern similar to that in jaundiced urine (Figure 10). This run was carried out for only 4 hours in order to minimize bilirubin decay. As with urine, one of the peaks of Folin-reactive material coincided with the bilirubin peak, and there was a peak of hexuronic acid in that same segment. A marked increase of Ninhydrin-reactive material was found after acid hydrolysis of the eluate from this segment. Thus on polyvinyl chloride the electrophoretic migration of bilirubin in urine and in dialyzates of uremic jaundiced plasma was the same.

2. Dog studies. Paper electrophoresis of normal dog serum with pure bilirubin added to a level of $6 \mathrm{mg}$ per $100 \mathrm{ml}$ showed pigment association only with albumin. Electrophoresis of sera from nine dogs with obstructive jaundice, however, showed one or two secondary bilirubin fractions, in addition to the main albumin-bilirubin zone. In most of the specimens the main secondary band was in the alpha globulin zone, but in a few specimens (Figure 11A), it was in the beta globulin zone. These secondary yellow zones yielded characteristic bilirubin derivatives with both the diazo and Fouchet reagents.
Urine specimens from five jaundiced dogs were subjected to electrophoresis on paper. The migration of conjugated bilirubin was qualitatively the same as in the human jaundiced urines. Bilirubin migrated in the beta and alpha globulin zones, and there was no stainable protein in these areas.

In two dogs plasma bilirubin electrophoretic patterns were compared before and 2 days after bilateral ureteral ligation. There was an increased proportion of bilirubin in the beta and alpha globulin zones in the uremic plasma (Figure $11 \mathrm{~B}$ ). After the uremic plasma specimens from these two animals were dialyzed, electrophoresis showed a decrease in the beta- and alphabilirubin.

\section{Discussion}

Dialysis and ultrafiltration of plasma. Hoover and Blankenhorn reported that plasma bilirubin was slightly dialyzable through collodion in jaundiced patients who had bilirubinuria, but not in patients with acholuric jaundice (3). Most subsequent investigators were unable to confirm their findings, however $(4,5,7)$. The later investiga- 

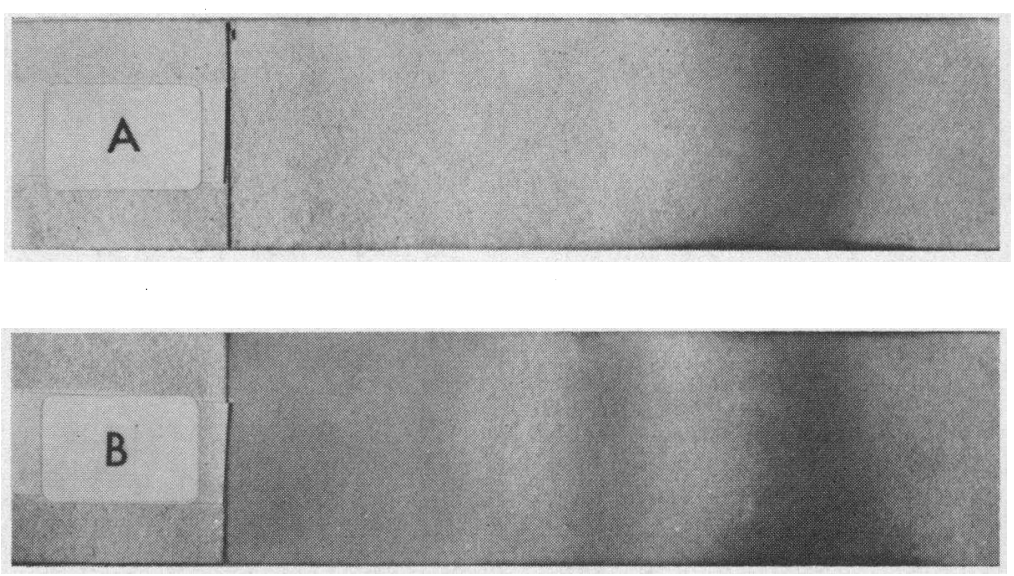

Fig. 11. Electrophoretic patterns of PLASMa CONJUGated BILIRUBin BEFORE AND AFTER UREMIA. Plasma from jaundiced dog 10-63. A. Before uremia. B. 2 days after bilateral ureteral ligation. Tris buffer, $\mathrm{pH} 8.6$. Diazo staining.

tors usually studied either normal plasma with added bilirubin, or specimens obtained from patients with predominant unconjugated hyperbilirubinemia. The nondialyzability of plasma unconjugated bilirubin, recently confirmed in several studies as well as the present one, is consistent with its lack of renal excretion (17-19).

The findings in our earlier renal function experiments in jaundiced dogs were consistent with a predominant process of glomerular filtration of conjugated bilirubin (9). Collodion sac ultrafiltrations of jaundiced plasma failed to yield ultrafilterable bilirubin in this laboratory. This may be explained by the observation that urinary bilirubin was adsorbed to the membrane when jaundiced urine was ultrafiltered through these collodion sacs. The use of cellophane casing permitted extensive dialysis of urinary bilirubin and also dialysis of a small fraction of plasma conjugated bilirubin.

Dialyses of plasma from patients with conjugated bilirubin levels below $9 \mathrm{mg}$ per $100 \mathrm{ml}$ are not reported because the dialyzate optical density measurements could not be translated accurately to concentrations. It has been possible, however, to verify the presence of bilirubin in dialyzates from plasma specimens with conjugated bilirubin levels as low as $5 \mathrm{mg}$ per $100 \mathrm{ml}$ by demonstrating absorption maxima at 433 to $450 \mathrm{~m} \mu$.

The proportion of plasma conjugated bilirubin that was dialyzable in both humans and dogs was large enough to account for urinary bilirubin excretion by a process of glomerular filtration. ${ }^{9}$ The precise proportion was difficult to define because of the methods of dialysis and of bilirubin estimation. The typical absorption spectra of the native pale yellow dialyzates and of their violet azo derivatives suggested that the dialyzable plasma pigment was bilirubin. The dialyzable percentages of total plasma bilirubin given in Tables I and II, however, are probably underestimates. Some methodologic factors resulted in underestimating the potential dialyzability, whereas others might have resulted in overestimation. The most important among the former was the inefficiency of 24-hour dialyses in which plasma specimens were dialyzed against equal (small) volumes of dialyzing fluid. The use of larger volumes of bath fluid permitted increased dialysis of plasma bilirubin (Figures 6 and 7), although the total amount dialyzable still remained a small fraction of the total plasma bilirubin in nonuremic specimens. The dialyzable fraction may also have been underestimated because of slight decay of bilirubin during dialysis. The use of the peak absorbance at 433 to $450 \mathrm{~m} \mu$ probably did not introduce a major error because the conformation

\footnotetext{
9 The values of $U_{B} V$ determined from the diazo reaction in urine are overestimates, at least to the extent of the nonbilirubin diazo blank. The sufficiency of the dialyzable plasma fraction as the source of urinary bilirubin is actually enhanced by any overestimation of $U_{B} V$.
} 
of the dialyzate spectral absorption curves (Figure 2) suggested that bilirubin was the major contributor to the peak absorbances. It was often not possible to estimate dialyzate bilirubin concentrations from the concentration of derivative azobilirubin in nonuremic specimens, because these optical densities were generally low.

The dialyzable plasma bilirubin fraction need not be the same as $C_{B} / G F R$ in order to support the glomerular filtration hypothesis. It would be fortuitous for an artificial membrane to have pore and permeability characteristics identical with those of the glomerular filter. Moreover, renal glomerular filtration involves ultrafiltration of plasma rather than dialysis. The cellophane membranes yielded less ultrafilterable than dialyzable plasma bilirubin ${ }^{10}$ (Figures 6 and 7 ). Finally, it is possible that some of the conjugated bilirubin which is filtered through the renal glomeruli may be reabsorbed, although our previous studies in dogs did not suggest the presence of a major tubular reabsorptive process.

The range of values for $C_{B} / G F R$ in the patients in this report corresponds to that reported by With (8) and by Wallace and Owen (20) in larger groups of jaundiced patients. The values for $C_{B} / G F R$ in the dogs (Table II) are in a range similar to that previously reported from this laboratory in a larger series of animals (9).

Wallace and Owen found that $C_{B} / C_{C r}$ was higher in patients with reduced filtration rates than in those with normal $\mathrm{C}_{\mathrm{Cr}}(20)$. We have also found that jaundiced patients and dogs with reduced GFR tend to have higher $\mathrm{C}_{\mathrm{B}} / \mathrm{GFR}$ values. The inclusion of several such patients in an earlier publication (2) gave $C_{B} / G F R$ values up to $0.9 \%$, and we have recently observed a jaundiced patient with $\mathrm{C}_{\mathrm{Cr}}$ of $9 \mathrm{ml}$ per minute whose $\mathrm{C}_{B} / \mathrm{C}_{\mathrm{Cr}}$ was $1.6 \%$. The conventional calculation of $\mathrm{C}_{\mathrm{B}}$ does not take into account the increased percentage of dialyzable plasma bilirubin that is present in patients with decreased GFR (Figure 4). Although such subjects may have increased glomerular permeability to a plasma bilirubinprotein complex, in our view the elevated $\mathrm{C}_{\mathbf{B}} /$ GFR depends simply upon the use of either total or direct-reacting plasma bilirubin as the de-

\footnotetext{
10 It was observed that urinary bilirubin was only about $50 \%$ ultrafilterable through these cellophane membranes, whereas it was 70 to $80 \%$ dialyzable.
}

nominator in the clearance formula rather than dialyzable plasma bilirubin.

If the dialyzable plasma fraction was unbound conjugated bilirubin in free equilibrium with the much larger nondialyzable fraction, repeated dialyses of the same plasma specimen with serial changes of bath fluid should yield, at equilibrium, similar bilirubin concentrations in successive dialyzates. The dialyzate bilirubin concentration decreased progressively until no more plasma bilirubin could be dialyzed, even though only a fraction of the total bilirubin had been removed. When samples of the same plasma were dialyzed against different volumes of buffer, the dialyzable bilirubin concentration was highest in the smallest dialyzate, although the calculated amount of dialyzable bilirubin was highest in the largest dialyzate. These findings suggested that most or perhaps all of the dialyzable fraction was not free conjugated bilirubin in equilibrium with the nondialyzable plasma bilirubin.

Ultracentrifugation studies. Ultracentrifugation of jaundiced human and dog urine resulted in sedimentation of bilirubin, and similar results were obtained with dialyzates of jaundiced urine and dialyzates of uremic jaundiced plasma ( $\mathrm{Ta}$ ble III). This suggested that the conjugated bilirubin in these dialyzates was bound to a carrier of high enough molecular weight so that the complex could sediment. The sedimentation gradients for Folin- and Ninhydrin-reactive material suggested that polypeptides were present in the dialyzates of both urine and plasma. These gradients do not necessarily mean that bilirubin is bound to the sedimenting polypeptides, but they are compatible with this hypothesis. It was inferred, therefore, that urinary conjugated bilirubin and the dialyzable fraction of plasma conjugated bilirubin are both complexed with a dialyzable carrier molecule(s), possibly a large polypeptide. The precipitation of bilirubin in dialyzates of urine and uremic plasma by $80 \%$ saturated ammonium sulfate also accords with the hypothesis that urinary bilirubin is bound to a small protein or large polypeptide.

Electrophoretic studies. The electrophoretic studies of jaundiced plasma and urine permitted further characterization of the bilirubin-carrier complex. There was a bilirubin band in the beta globulin zone in humans, in addition to the major 


\section{BILIRUBIN - PAPER ELECTROPHORESIS}

BILIRUBIN ADDED TO NORMAL PLASMA

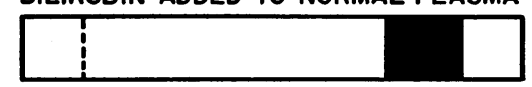

OBSTRUCTIVE JAUNDICE PLASMA

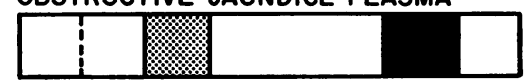

OBSTRUCTIVE JAUNDICE URINE

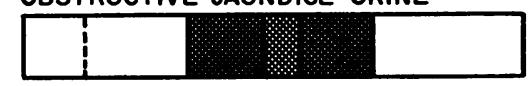

OBSTRUCTIVE JAUNDICE UREMIC PLASMA

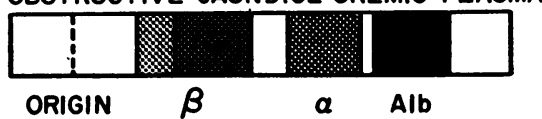

Fig. 12. Electrophoretic patterns of plasma CONJUGATED AND UNCONJUGATED BILIRUBIN AND URINARY BILIRUBIN. A diagram showing the relative proportions of bilirubin migrating in the albumin, alpha and beta globulin zones. Note the small proportion of beta migrating conjugated bilirubin in nonuremic jaundiced plasma and the increase in beta and alpha migrating bilirubin in uremic jaundiced plasma, paralleling the urinary electrophoretic migration of conjugated bilirubin.

one in the albumin zone, and in dogs in the alpha globulin zone (sometimes alpha and beta).'

Earlier plasma bilirubin electrophoretic studies concurred that most of the pigment migrated with albumin. It was indicated in some reports that all the bilirubin was albumin-bound $(4,18$, 21-23), and in others it was suggested that small amounts migrated in the alpha $(19,24-26)$ or beta globulin zones $(26,27)$. In most of those studies the electrophoreses were made using either normal plasma with added bilirubin or abnormal plasma with high levels of unconjugated bilirubin. The present results accord with the earlier findings that up to bilirubin levels of about $40 \mathrm{mg}$ per $100 \mathrm{ml}$, albumin seems to be the only plasma protein that binds unconjugated bilirubin in perceptible amounts.

The paper electrophoretic patterns of bilirubin in jaundiced urine and uremic jaundiced plasma from humans and dogs were qualitatively similar and will be considered together. The diagrams in Figure 12 summarize the findings. Urinary bilirubin migrated mainly in a broad zone of beta and alpha globulin mobility, although there was no stainable protein on the paper strips. In some specimens the color was more intense in the beta zone (usually in dog urine), and in others in the alpha zone (usually in human urine), but the relative proportions were variable. The zone of urinary beta bilirubin migration was slightly faster than the secondary beta bilirubin band present in nonuremic jaundiced human plasma. If the dialyzable plasma bilirubin fraction was the source of urinary bilirubin, it might be expected that its increment in the plasma in subjects with renal failure could be appreciated electrophoretically in the beta and alpha zones. The electrophoretic patterns of uremic jaundiced plasma in four patients and two dogs bore out that prediction. This pattern was shown to differ from the preuremic pattern (Figures 9 and 11). In all of these specimens it was shown that at least some of the excess uremic beta and alpha bilirubin could be removed by in vitro dialysis (Figure 9C). The electrophoretic migration of conjugated bilirubin in concentrated dialyzates of uremic jaundiced plasma was shown to conform with the results of the foregoing indirect studies.

These results indicated that the dialyzable fraction of plasma conjugated bilirubin was the source of urinary conjugated bilirubin and that it was complexed with a carrier molecule(s) which exhibited electrophoretic mobility on paper in the beta and alpha globulin zones.

On polyvinyl chloride, as on cellulose acetate and agar gel (28), electrophoresis of jaundiced urine and urine dialyzates exhibited predominant prealbumin migration of conjugated bilirubin. Electrophoretic migration may vary in different media (29), accounting for this difference from the pattern found on paper electrophoresis. On polyvinyl chloride the migration of plasma dialyzable bilirubin and urine bilirubin was concordant, both exhibiting prealbumin mobility.

The unavailability of pure bilirubin conjugates has hampered efforts to elucidate the problem of their binding to plasma proteins. The present studies indicate the existence of qualitative differences in protein binding between conjugated and unconjugated bilirubin. A solution of the quantitative aspects of the problem must await other approaches. 


\section{Summary}

Conjugated bilirubin was previously shown to be excreted mainly by glomerular filtration in jaundiced dogs. The present studies were undertaken to characterize the filtered urinary bilirubin in subjects with obstructive jaundice.

When plasma from subjects with obstructive jaundice was dialyzed in cellophane sacs against an equal volume of buffer, a small fraction of the plasma conjugated bilirubin was found to be dialyzable. This dialyzable portion averaged $0.6 \%$ in humans and $1.6 \%$ in dogs with normal renal function. In each species this was as large as, or larger than, the fraction of plasma bilirubin cleared by the kidneys, suggesting that the dialyzable plasma fraction is filterable through the renal glomeruli and that it is unnecessary to invoke tubular secretion to explain renal excretion of conjugated bilirubin. The dialyzable plasma bilirubin fraction increased in jaundiced subjects with renal insufficiency.

Ultracentrifugation of dialyzates of jaundiced urine and jaundiced uremic plasma produced a gradient of both conjugated bilirubin and polypeptide. The conjugated bilirubin in these dialyzates was precipitable with $80 \%$ saturated ammonium sulfate, and these precipitates could be redissolved in water. It seems likely that the dialyzable conjugated bilirubin in both fluids is combined with another substance, possibly a polypeptide.

Paper electrophoresis of plasma from subjects with obstructive jaundice showed migration of bilirubin predominantly with albumin. There was a minor secondary bilirubin band in the beta globulin zone in humans and in the alpha, or occasionally beta, globulin zone in dogs. Urinary bilirubin migrated in a broad region comprising the beta and alpha globulin zones. In subjects with obstructive jaundice and renal failure, an increased proportion of the plasma bilirubin migrated in the beta and alpha globulin zones. Bilirubin appearing in the beta and alpha zones could be partially dialyzed from these plasma specimens in vitro. Electrophoresis of concentrated jaundiced urine and plasma dialyzates prepared by ammonium sulfate precipitation showed bilirubin migration in the beta and alpha globulin zones.

On polyvinyl chloride electrophoresis, there was predominant prealbumin migration of bilirubin in jaundiced urine and in concentrated dialyzates of uremic jaundiced plasma. These prealbumin zones contained hexuronic acid, and Folin- and Ninhydrin-reactive material.

The basis for the difference in renal excretion between conjugated and unconjugated bilirubin resides in the dialyzability of a small fraction of the plasma conjugated bilirubin and the nondialyzability of plasma unconjugated bilirubin. This difference is, in turn, attributable to the binding of a small fraction of plasma conjugated bilirubin to a nonalbumin plasma constituent of low molecular weight.

\section{Acknowledgments}

We are grateful to Alma Annexy, Luis Leon, and Joseph DeVito for their capable technical assistance and to Dr. I. H. Scheinberg for the use of equipment in his laboratory.

\section{References}

1. Fulop, M., J. Sandson, and P. Brazeau. The mechanism of excretion of bilirubin by the kidney (abstract). J. clin. Invest. 1964, 43, 1244.

2. Fulop, M., J. Sandson, and P. Brazeau. Dialysability of conjugated bilirubin from plasma of jaundiced dogs and patients (preliminary communication). Lancet 1964, 1, 1017.

3. Hoover, C. F., and M. A. Blankenhorn. Dissociated jaundice. Arch. intern. Med. 1916, 18, 289.

4. Snapper, I., and W. M. Bendien. On the physicochemical condition of the bilirubin in the bloodserum and urine. Acta med. scand. 1938, 98, 77.

5. Barac, G. Cénapse albumino-bilirubinique et élimination rénale de la bilirubine. Bull. Soc. Chim. biol. (Paris) 1947, 29, 96.

6. Blondheim, S. H., D. Lathrop, and J. Zabriskie. Effect of light on the absorption spectrum of jaundiced serum. J. Lab. clin. Med. 1962, 60, 31.

7. Gregory, R. L., and M. Andersch. The filtrability of bilirubin in obstructive jaundice. J. Lab. clin. Med. $1937,22,1111$.

8. With, T. K. Bilirubin in urine and other secretions apart from the bile and in the cerebrospinal and eye liquors. Acta physiol. scand. 1945, 10, 355.

9. Fulop, M., and P. Brazeau. The renal excretion of bilirubin in dogs with obstructive jaundice. J. clin. Invest. 1964, 43, 1192.

10. Weber, A. Ph., and L. Schalm. Quantitative separation and determination of bilirubin and conjugated bilirubin in human serum. Clin. chim. Acta 1962, 7, 805.

11. Malloy, H. T., and K. A. Evelyn. The determination of bilirubin with the photoelectric colorimeter. J. biol. Chem. 1937, 119, 481. 
12. Moore, S., and W. H. Stein. Photometric Ninhydrin method for use in the chromatography of amino acids. J. biol. Chem. 1948, 176, 367.

13. Dische, Z. A new specific color reaction of hexuronic acids. J. biol. Chem. 1947, 167, 189.

14. Toribara, T. Y., A. R. Terepka, and P. A. Dewey. The ultrafiltrable calcium of human serum. I. Ultrafiltration methods and normal values. $\mathrm{J}$. clin. Invest. 1957, 36, 738.

15. Grabar, P., and C. A. Williams, Jr. Méthode immuno-électrophorétique d'analyse de mélanges de substances antigéniques. Biochim. biophys. Acta (Amst.) 1955, 17, 67.

16. Ingbar, S. H., and N. Freinkel. Regulation of the peripheral metabolism of the thyroid hormones. Recent Progr. Hormone Res. 1960, 16, p. 353.

17. Odell, G. B. Studies in kernicterus. I. The protein binding of bilirubin. J. clin. Invest. 1959, 38, 823.

18. Ostrow, J. D., and R. Schmid. The protein-binding of $\mathrm{C}^{14}$-bilirubin in human and murine serum. $\mathrm{J}$. clin. Invest. 1963, 42, 1286.

19. Watson, D. The transport of bile pigments: the binding of sodium bilirubinate to plasma protein. Clin. Sci. 1962, 22, 435.

20. Wallace, D. K., and E. E. Owen. An evaluation of the mechanism of bilirubin excretion by the human kidney. J. Lab. clin. Med. 1964, 64, 741.
21. Coolidge, T. B. Chemistry of the van den Bergh reaction. J. biol. Chem. 1940, 132, 119.

22. Barac, G. Interactions of bilirubin with plasma proteins, and the state of bilirubin in normal human plasma. Arch. int. Physiol. 1953, 61, 129.

23. Bourrillon, $\mathrm{R}$. Isolement et propriétés du complexe bilirubinsérumalbumine du sérum. Bull. Soc. Chim. biol. (Paris) 1957, 39, 385.

24. Gray, C. H., and R. A. Kekwick. Bilirubin-serum protein complexes and the van den Bergh reaction. Nature (Lond.) 1948, 161, 274.

25. Martin, N. H. Preparation and properties of serum and plasma proteins. XXI. Interactions with bilirubin. J. Amer. chem. Soc. 1949, 71, 1230.

26. Klatskin, G., and L. Bungards. Bilirubin-protein linkages in serum and their relationship to the van den Bergh reaction. J. clin. Invest. 1956, 35, 537.

27. Westphal, U., H. Ott, and P. Gedigk. An welche Komponenten der Serumproteine ist das Bilirubin gebunden? Hoppe-Seylers Z. physiol. Chem. 1950, 285,200

28. Sandson, J., and M. Fulop. Unpublished observations.

29. Block, R. J., E. L. Durrum, and G. Zweig. A Manual of Paper Chromatography and Paper Electrophoresis, 2nd ed. New York, Academic Press, 1958 , p. 501. 